\title{
Analysis and Load-carrying Capacity Estimation of Existing Railway Filler-beam Deck Bridges
}

\author{
Josef Vičan, Jozef Gocál, Jaroslav Odrobiňák, Richard Hlinka \\ University of Žilina \\ Civil Engineering Faculty, Department of Structures and Bridges \\ e-mail: josef.vican@fstav.uniza.sk
}

\begin{abstract}
In the paper, the actual condition of several existing concrete railway bridges with encased steel beams is discussed. This structural type represents relatively often solution for small span railway bridges in Slovakia. The main conclusions from inspections and in-situ diagnostics are published together with the results of the loadcarrying capacity calculation on the basis of new European codes. Despite of well-known disadvantages, the bridges with filler-beam decks are still demanded by railway authorities because of their big stiffness and small construction depth.
\end{abstract}

Key words: filler-beam deck bridge, diagnostics, design and reconstruction of bridges with encased beams

\section{Introduction}

Filler-beam deck bridges (see Figure 1) represent a traditional bridge structural system used for small span railway bridges in Slovakia and also in other European countries. Despite of their well-known disadvantages, such as big weight, ineffective utilization of materials and problems with durability, the filer-beam deck bridges are still demanded by railway administrators. The main argument for applying this type of bridges is their big stiffness that makes them advantageous especially from the viewpoint of more and more strict requests for deformations and vibrations of bridges designed and reconstructed in frame of modernisation of railway corridors. Small structural depth represents another unquestionable advantage of the filer-beam deck bridges and also a lot of experiences with their design and maintenance argue for their application.

Effective application of the filler-beam railway bridges has been supported in more advanced European countries also by normative activities of UIC 1997 [1], Deuchte Bahn [2] and Czech Railways [3]. The situation in Slovakia is a bit more complicated, where either the older guideline [4] based on the allowable stress method is applied for design of bridges with 
encased beams, or the appropriate provisions of EN 4 [5] are used. Regarding to load-carrying capacity calculation of this type of bridges, the situation is similar, when either the older guideline for load-carrying capacity [6] or the newer proposal of guideline [7] may be applied. Therefore, results of research activities in this field were presented within last period [10], [11] describing new possibilities of the bridge cross sectional arrangement and material optimal utilization.

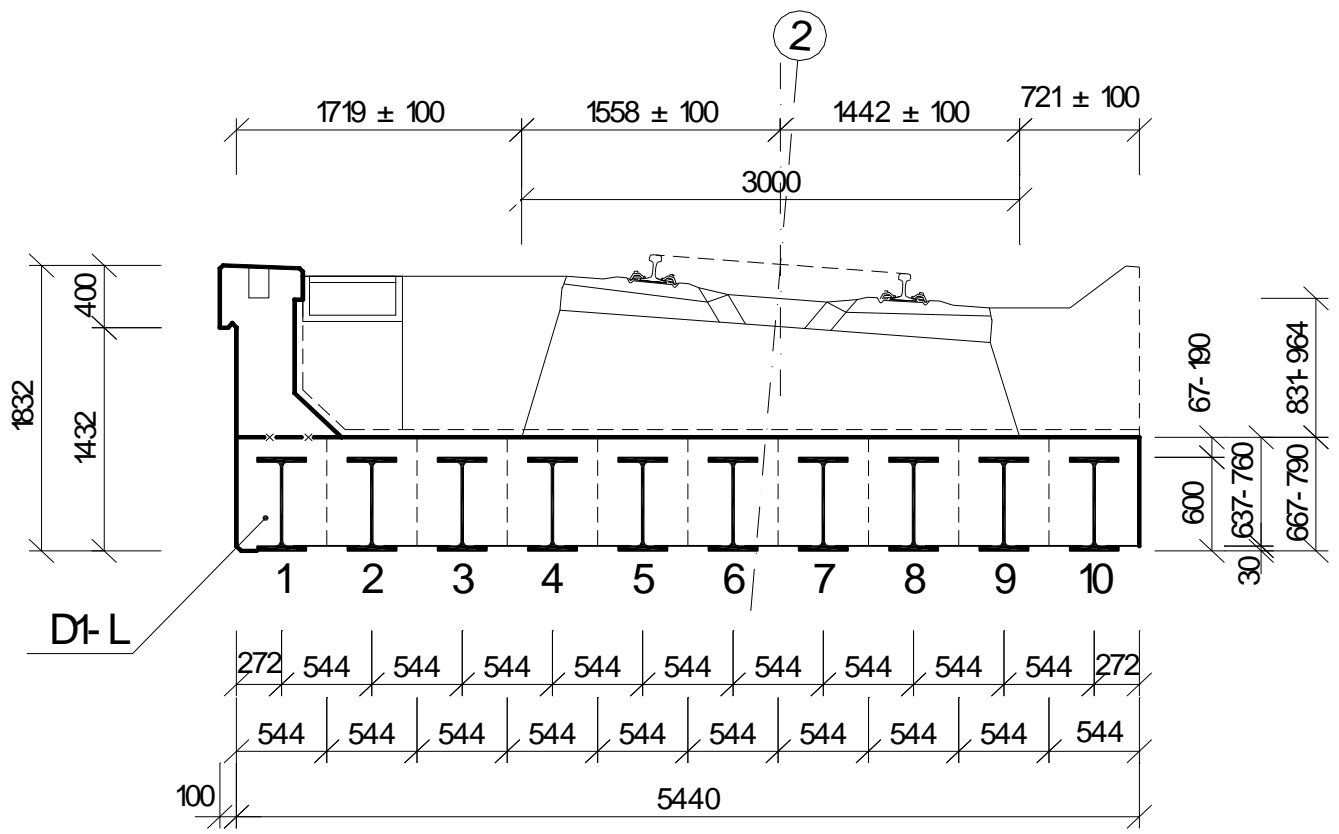

Figure 1: Typical cross section of the filler-beam bridge deck

\section{Bridge actual condition}

Conclusions of diagnostic inspections of six filler beam railway bridges are summarised in this part. Three of them are situated on tap line going to a factory and their diagnostics were needed to process calculations of the bridges in order to determine their load-carrying capacity (LCC) and to verify the safe passage capability (SPC) of the rail vehicle of class D4 according to guidelines [6] or [7]. The other three bridges are situated in main line of Slovak railways and their diagnostics were performed as a base for processing the documentation for general planning procedure within the modernisation of the appropriate track section for track speed $160 \mathrm{~km} \cdot \mathrm{h}^{-1}$. Basic data of the mentioned bridge superstructures are presented in Table 1. All the bridge decks were simply supported on asphalt strips and all the abutments of bridges were either concrete or stone.

Based on the inspection results, a few conclusions may be stated out. The older bridges having fully encased steel beams shows strong surface corrosion of all bottom flanges. The concrete cover no longer serves as a protective layer and it consecutively falls away. With regards to the efflorescence observed on all the inspected bridges it may be deduced that the 
insulation of the superstructure under ballast is in bad condition. The bridges situated far from villages show signs of bad maintenance, the sides of their superstructures are moss-grown and the decks are moss-grown and weedy.

Table 1: Basic data of inspected bridges

\begin{tabular}{|c|c|c|c|c|c|c|c|c|c|}
\hline $\begin{array}{c}\text { Bridge } \\
\text { designation }\end{array}$ & $\begin{array}{l}\text { Track } \\
\text { type }\end{array}$ & $\begin{array}{l}\text { Obstacle } \\
\text { type }\end{array}$ & $\begin{array}{l}\text { Number } \\
\text { of spans }\end{array}$ & $\begin{array}{c}\text { Deck } \\
\text { age } \\
\text { (years) }\end{array}$ & $\begin{array}{c}\text { Angle } \\
\text { of } \\
\text { crossing } \\
\end{array}$ & $\begin{array}{c}\text { Clearance } \\
\text { (m) }\end{array}$ & $\begin{array}{c}\text { Steel } \\
\text { beams }\end{array}$ & $\begin{array}{l}\text { Protection } \\
\text { of bottom } \\
\text { flanges }\end{array}$ & $\begin{array}{c}\text { Rehabilitation } \\
\text { during } \\
\text { service }\end{array}$ \\
\hline $\mathrm{T} 1$ & $\begin{array}{l}\text { tape } \\
\text { line }\end{array}$ & road & 1 & 25 & $56^{\circ}$ & 9,08 & $\begin{array}{c}\text { welded } \\
400 \\
\mathrm{~mm}\end{array}$ & coat & none \\
\hline $\mathrm{T} 2$ & $\begin{array}{l}\text { tape } \\
\text { line }\end{array}$ & creek & 1 & 25 & $72^{\circ}$ & 6,90 & $\begin{array}{c}\text { hot } \\
\text { rolled I } \\
360\end{array}$ & coat & none \\
\hline $\mathrm{T} 3$ & $\begin{array}{l}\text { tape } \\
\text { line }\end{array}$ & river & 1 & 25 & $77^{\circ}$ & 12,00 & $\begin{array}{l}\text { welded } \\
600 \\
\mathrm{~mm}\end{array}$ & coat & none \\
\hline \multirow{3}{*}{ M1 } & \multirow{3}{*}{$\begin{array}{l}\text { main } \\
\text { line }\end{array}$} & \multirow{3}{*}{ river } & \multirow{3}{*}{3} & \multirow{3}{*}{57} & \multirow{3}{*}{$90^{\circ}$} & 6,61 & rails & concrete & none \\
\hline & & & & & & 10,00 & $\begin{array}{c}\text { hot } \\
\text { rolled I } \\
500\end{array}$ & concrete & none \\
\hline & & & & & & 6,65 & rails & concrete & none \\
\hline M2 & $\begin{array}{l}\text { main } \\
\text { line }\end{array}$ & creek & 1 & 94 & $90^{\circ}$ & 4,97 & rails & concrete & cornices \\
\hline M3 & $\begin{array}{l}\text { main } \\
\text { line }\end{array}$ & creek & 1 & 94 & $90^{\circ}$ & 2,97 & rails & concrete & cornices \\
\hline
\end{tabular}

Table 2: Bridge deck damages and bridge evaluation

\begin{tabular}{ccccccccc}
\hline $\begin{array}{c}\text { Bridge } \\
\text { designation }\end{array}$ & $\begin{array}{c}\text { Deviations } \\
\text { of deck } \\
\text { parameters } \\
\text { (mm) }\end{array}$ & $\begin{array}{c}\text { Bottom } \\
\text { flanges } \\
\text { corrosion }\end{array}$ & $\begin{array}{c}\text { Dropped } \\
\text { out } \\
\text { concrete } \\
\text { cover }\end{array}$ & $\begin{array}{c}\text { Efflores } \\
\text { cence }\end{array}$ & $\begin{array}{c}\text { Crack in } \\
\text { working } \\
\text { joint }\end{array}$ & $\begin{array}{c}\text { Mainte } \\
\text { nance } \\
\text { quality }\end{array}$ & $\begin{array}{c}\text { Damage } \\
\text { influence } \\
\text { on SPC }\end{array}$ & $\begin{array}{c}\text { Bridge } \\
\text { evaluation }\end{array}$ \\
\hline T1 & $<20$ & medium & - & medium & open & good & none & good \\
\hline T2 & $<20$ & medium & - & medium & open & good & none & good \\
\hline T3 & $<20$ & medium & - & medium & open & good & none & good \\
\hline M1 & $20-50$ & strong & local & strong & open & good & none & satisfactory \\
\hline M2 & $<20$ & strong & surface & strong & open & bad & none & bad \\
\hline M3 & $20-50$ & strong & local & strong & open & bad & none & bad \\
\hline
\end{tabular}

Left part of Figure 2 illustrates the condition of bottom surface of the bridge M2 with the high degree of degradation due to corrosion and efflorescence. 

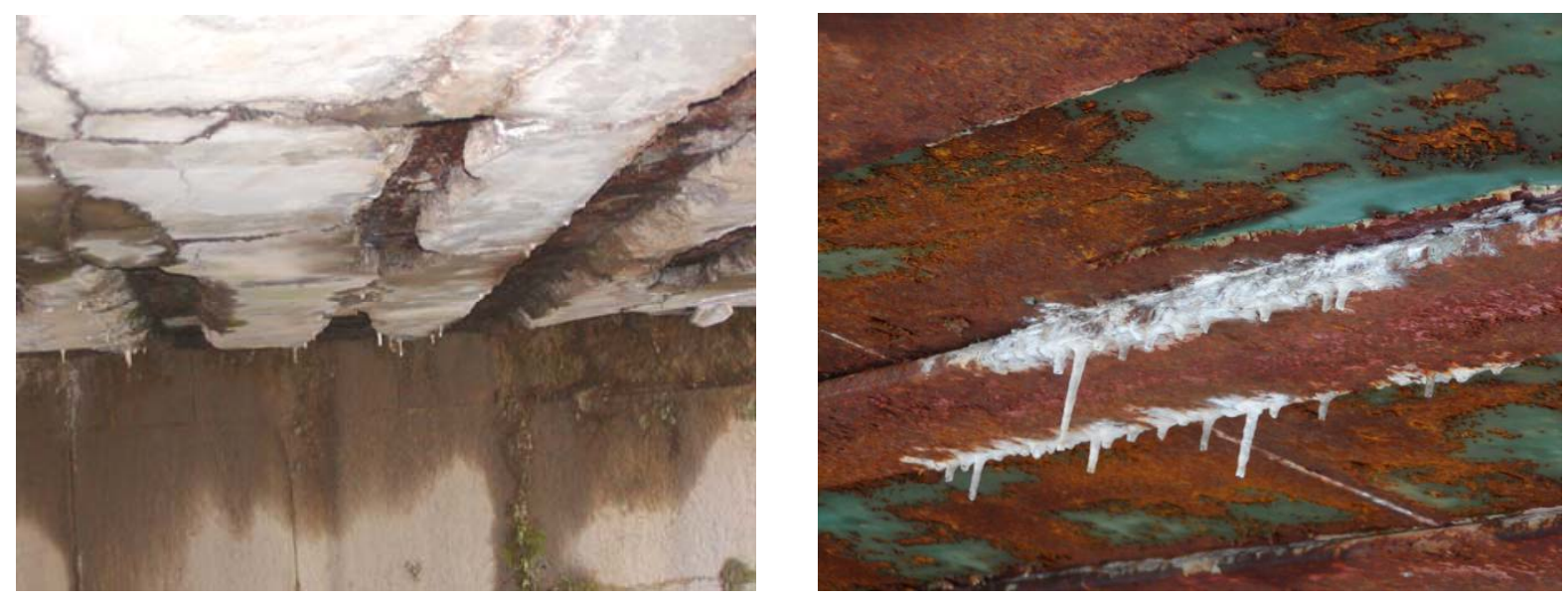

Figure 2: Characteristic view of the bottom surface of the bridges a) with concrete cover b) with shuttering plates

The stage of bottom surface of the bridge T1, at which the smallest degree of corrosion of the bottom flanges and shuttering steel plates was observed, is also presented in Figure 2 on the right.

In all cases of the inspected bridges there are evident horizontal cracks at the working joints situated between the bridge deck and side cornices. These cracks occur as a result of inaccurate theoretical assumptions related to the model of the superstructure during the bridge design. The side cornices, creating a channel for ballast bed together with the bridge deck, used to be considered only as an additive load on bridge deck. However, rather high reinforced concrete cornices cooperate with the outer beams consisting of the outer steel girder and cooperating concrete deck. As a result of that, the superstructure tends to act initially as a double-beam bridge with bottom deck. Since the outer composite beams were not originally designed for the bending moments resulting from such behaviour, the structure naturally reacts by relaxation of stresses in the most critical section.
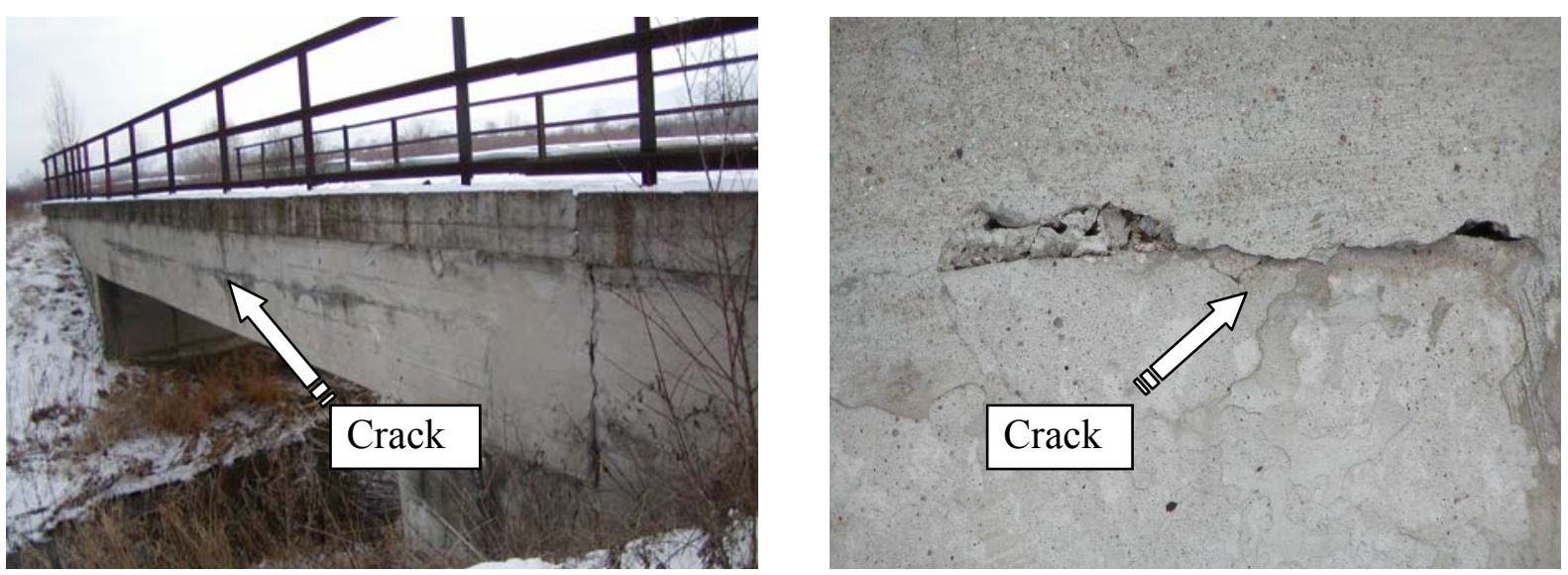

Figure 3: Example of the longitudinal crack at the working joint between the bridge deck and cornice 
Longitudinal crack, which creates along the working joint in consequence of longitudinal shear force between the cornice and deck, allows quasi-independent bending behaviour of the deck and cornice. Figure 3 on the left shows the side view of the bridge T2 with marked longitudinal crack and the detail view of the crack on the right.

From the viewpoint of actual behaviour it may be said that the superstructure comes near to the assumed theoretical model. From the durability point of view, the open longitudinal crack, often very marked and visible even from a few meters, represents an unfavourable factor especially in the area of insulation folds.

From experiences obtained from bridge diagnostics it can be stated out that the condition of filler-beam deck bridges in other sections of railway tracks in Slovakia with similar age may be assumed to be very close to that one mentioned above.

\section{Structural analysis of existing bridge deck}

As it was mentioned above, the results of diagnostics of bridges designated as T1, T2 and T3 were used for structural analysis of the bridge filler-beam decks. At the time of design of those bridges a simplified planar model used to be applied for determining the response of superstructure to traffic load. This model was based on a conception of effective distribution width, which limited the region of steel girders that should have been considered to transfer the vertical live loads. Then, all the girders within the effective width were assumed to be stressed equally. Of course, this approximate model cannot describe the real behaviour of the bridge sufficiently and might be used today only for preliminary or orientation calculation. In order to obtain a realistic view of the actual static behaviour of the superstructure in the longitudinal direction as well as in the transversal direction, the three-dimensional grid or plate model is recommended to be applied for calculating the response of superstructure to traffic load.

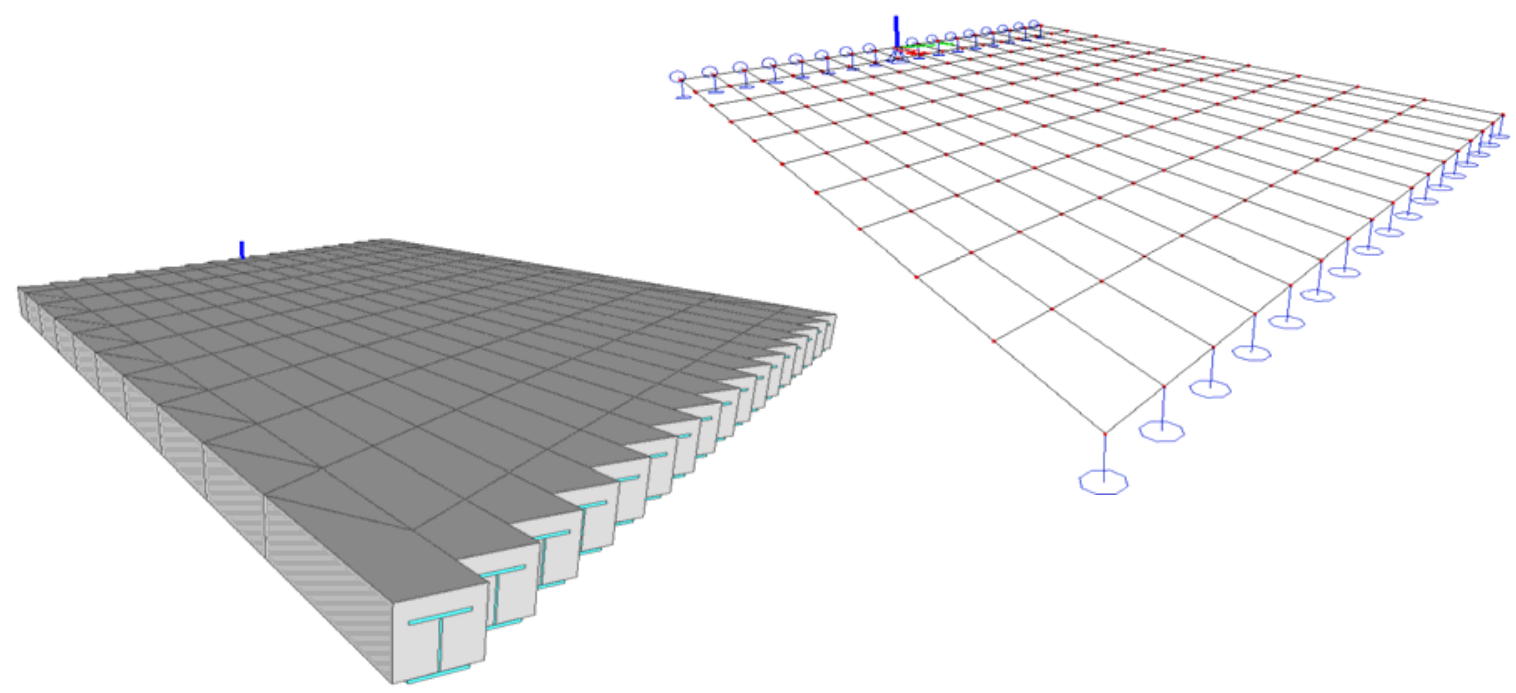

Figure 4: Geometric scheme and visualization of the 3D-grid model of the slanted bridge deck 
With regards to the inspection results, the cornice, which does not create an integrated part of the deck superstructure, may be taken into account as an additive load on the deck. Example of the 3D grid model of the slant bridge superstructure T1 processed in the software SCIA Engineering using the finite element method is presented in Figure 4.

The structural analysis were performed according to guideline [9] based on the concept of Eurocode 4 [5]. The encased girders are considered as composite steel and concrete beams. Their bending resistance may be determined assuming either the plastic or elastic distribution of stresses through the depth of beams. The choice of the calculation method was influenced by available information about actual reinforcement of the cross section, especially the transversal reinforcement passed through the holes in the webs of steel girders. This reinforcement is quite hardly detectable, especially when the steel plates were used as a permanent formwork.

In all three cases of the presented bridges very good data were available. In addition to the inspection results almost complete project documentation of these bridges was available too. The quality of concrete was checked on the basis of measurements "in situ" by means of Schmidt hammer [8]. The conclusions from structural analysis in the form of relevant loadcarrying capacities are presented in Table 3, in which the decisive bridge load-carrying capacity is underlined by bold face. From the table it follows that all three bridges satisfy the requirement of load-carrying capacity corresponding to effects of the load model LM 71 . Consequently, also the requirement of the safe passage capability of the rail vehicle of class D4 according to guidelines [6] and [9] was satisfied.

Table 3: Preview of input data and conclusions from static calculations

\begin{tabular}{|c|c|c|c|c|c|c|c|c|}
\hline \multirow{3}{*}{$\begin{array}{l}\text { Bridge } \\
\text { desig- } \\
\text { nation }\end{array}$} & \multirow{3}{*}{$\begin{array}{c}\text { Bridge } \\
\text { span (m) }\end{array}$} & \multirow{3}{*}{$\begin{array}{c}\text { Steel } \\
\text { beams }\end{array}$} & \multirow{3}{*}{$\begin{array}{c}\text { Girder } \\
\text { spacing } \\
(\mathrm{mm})\end{array}$} & \multirow{3}{*}{$\begin{array}{l}\text { Concrete } \\
\text { class }\end{array}$} & \multicolumn{4}{|c|}{ Load-carrying capacity } \\
\hline & & & & & \multicolumn{3}{|c|}{ Longitudinal direction } & \multirow{2}{*}{$\begin{array}{l}\text { Transversa } \\
1 \text { direction }\end{array}$} \\
\hline & & & & & Bending & Shear & Deflection & \\
\hline $\mathrm{T} 1$ & 10.44 & $\begin{array}{l}\text { welded } \\
400 \mathrm{~mm}\end{array}$ & 450 & $\mathrm{C} 20 / 25$ & 2.13 & 3.19 & 2.89 & 1.40 \\
\hline $\mathrm{T} 2$ & 8.00 & $\begin{array}{c}\text { hot rolled } \\
\text { I } 360\end{array}$ & 385 & $\mathrm{C} 20 / 25$ & 1.21 & 3.69 & 2.74 & - \\
\hline $\mathrm{T} 3$ & 13.20 & $\begin{array}{l}\text { welded } \\
600 \mathrm{~mm}\end{array}$ & 450 & $\mathrm{C} 20 / 25$ & 1.85 & 4.28 & 3.00 & 1.98 \\
\hline
\end{tabular}

\section{Design of new filler-beam deck}

The other three bridges, designated as M1, M2 and M3, are situated in the main track Bratislava - Žilina, on which the works connected with their modernisation to track speed $160 \mathrm{~km} \cdot \mathrm{h}^{-1}$ are gradually realised. Since within the preparation of documentation for general planning procedure it was decided to replace these bridge objects by the new ones, the structural analysis of the existing superstructures was not performed. The complete reconstruction was evocated by unsatisfactory parameters in term of required flood level as well as by change of the track geometry. As an example of the new superstructure realization, 
rebuilding the bridge designated as M1 is presented. The reinforced concrete deck with encased steel beams was chosen again as an optimal structural system for the design of superstructure. Within the choice of the deck cross sectional shape a few variants were considered, which are presented in Figure 5.
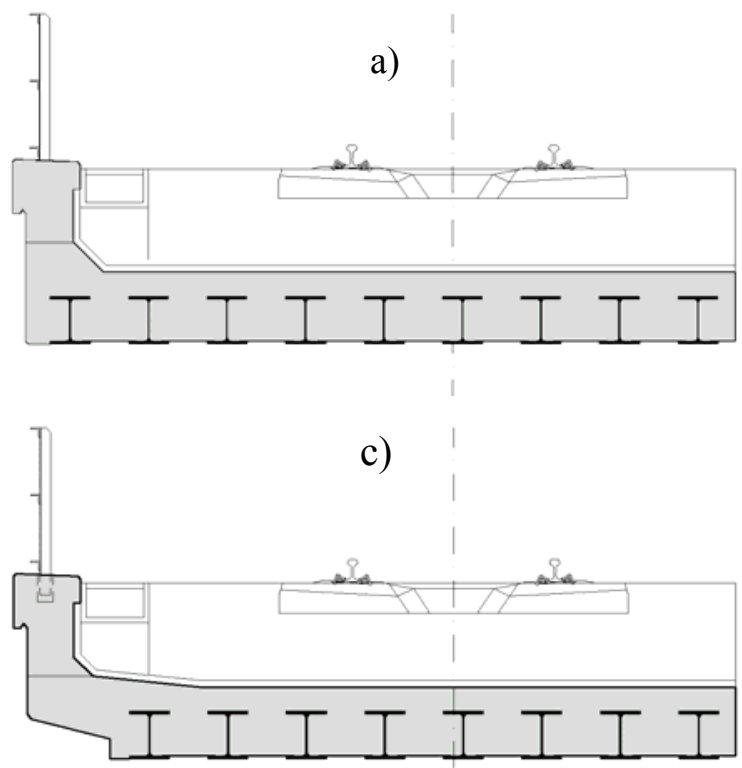

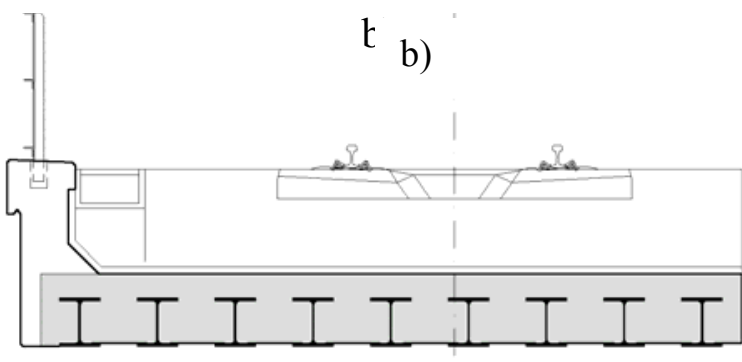

d)

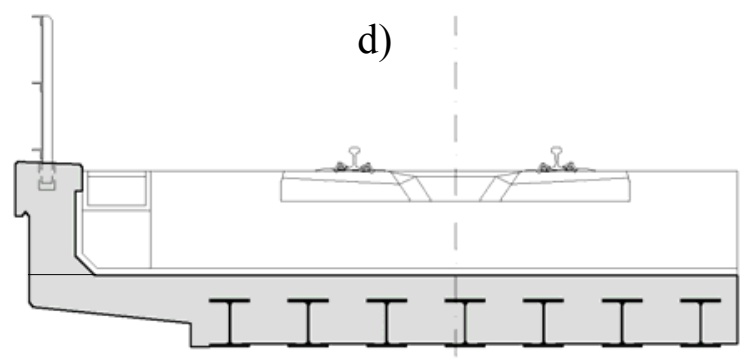

Figure 5: Considered shapes of bridge deck cross section

Figure 5a shows the classic shape of cross section that leads to creating the cracks in the working joints between the bridge deck and cornices within service. Figure $5 \mathrm{~b}$ presents application of the precast cornice that is quite heavy and its anchoring is rather problematic. Better solutions are presented in Figures $5 \mathrm{c}$ and $5 \mathrm{~d}$, where the cornice part is solved as lightened bracket without encased beams. The Figure $5 \mathrm{c}$ although represents the variant that was applied for rebuilding the bridge designated as M1. Besides of the structure lightening, this solution has a favourable effect on the slab action of the bridge. Providing that the support is proposed only under the steel beams, the bracket does not cooperates in longitudinal direction on transferring vertical loads.

For that reason discussed in the chapter 3, the three-dimensional plate-member model was applied for global analysis of the bridge deck, which was considered as a ribbed slab. Geometric scheme of the middle span superstructure model processed in software using the finite element method is presented in Figure 6.

The presented model respects automatically possible non-uniform load distribution in the longitudinal as well as in the transversal direction. The effect of slip between concrete and steel beams due to the longitudinal flexure is neglected. Effect of shear lag, which is negligible because of small distances between the steel beams, is automatically considered by the FEM model too. The internal forces are determined by elastic analysis and the effect of cracks in concrete are neglected. When the more usual bridge construction without temporary support is assumed in the bridge design, the dead loads have to be separated to two parts. The first part, which is transferred only by steel beams, consists of weight of the steel beams and 
other steel components, weight of the unhardened concrete and weight of the permanent formwork. The second part of dead loads, consisting of weight of cornices, insulation, and the ballasted track, as well as all the live loads are then transferred by the composite cross section.

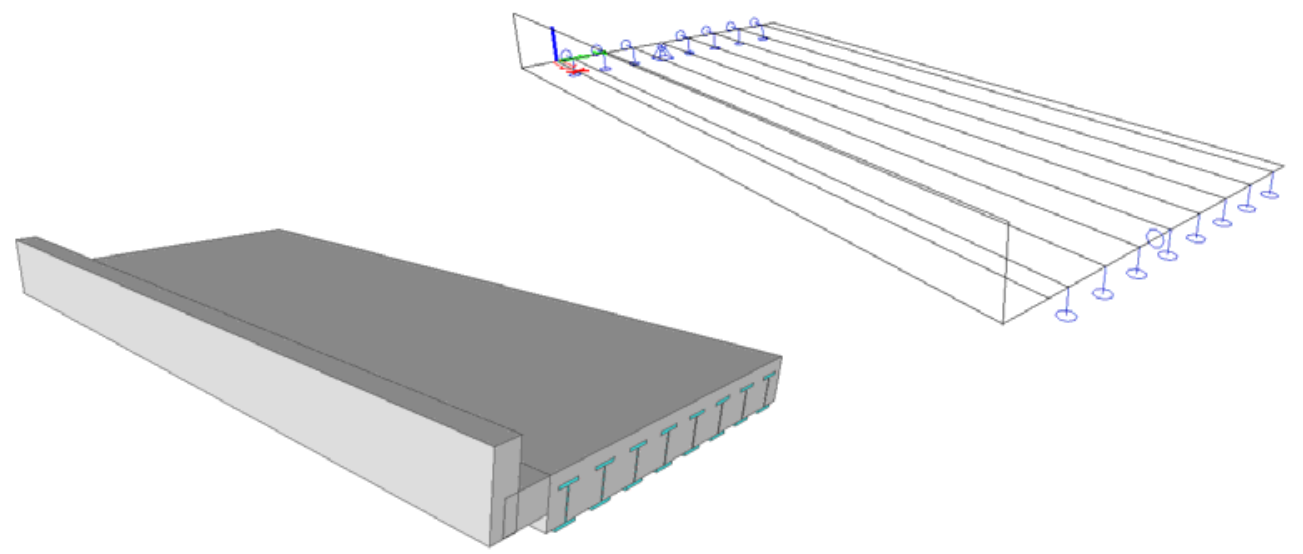

Figure 6: Geometric scheme and visualization of the 3D-plate-member model of the filler-beam bridge deck

The availability of standard prescriptions for design of this type of bridges at the present time in Slovakia is discussed in the introductory chapter of the paper. With regards to this fact, the structural analysis was performed according to Eurocode 4 [5], [7]. For the design of new filler-beam bridges it is advisable to apply elastic global analysis and plastic cross sectional resistance of the deck for the ultimate limit state verification, at which the composite steel and concrete cross section could be designed more effectively.

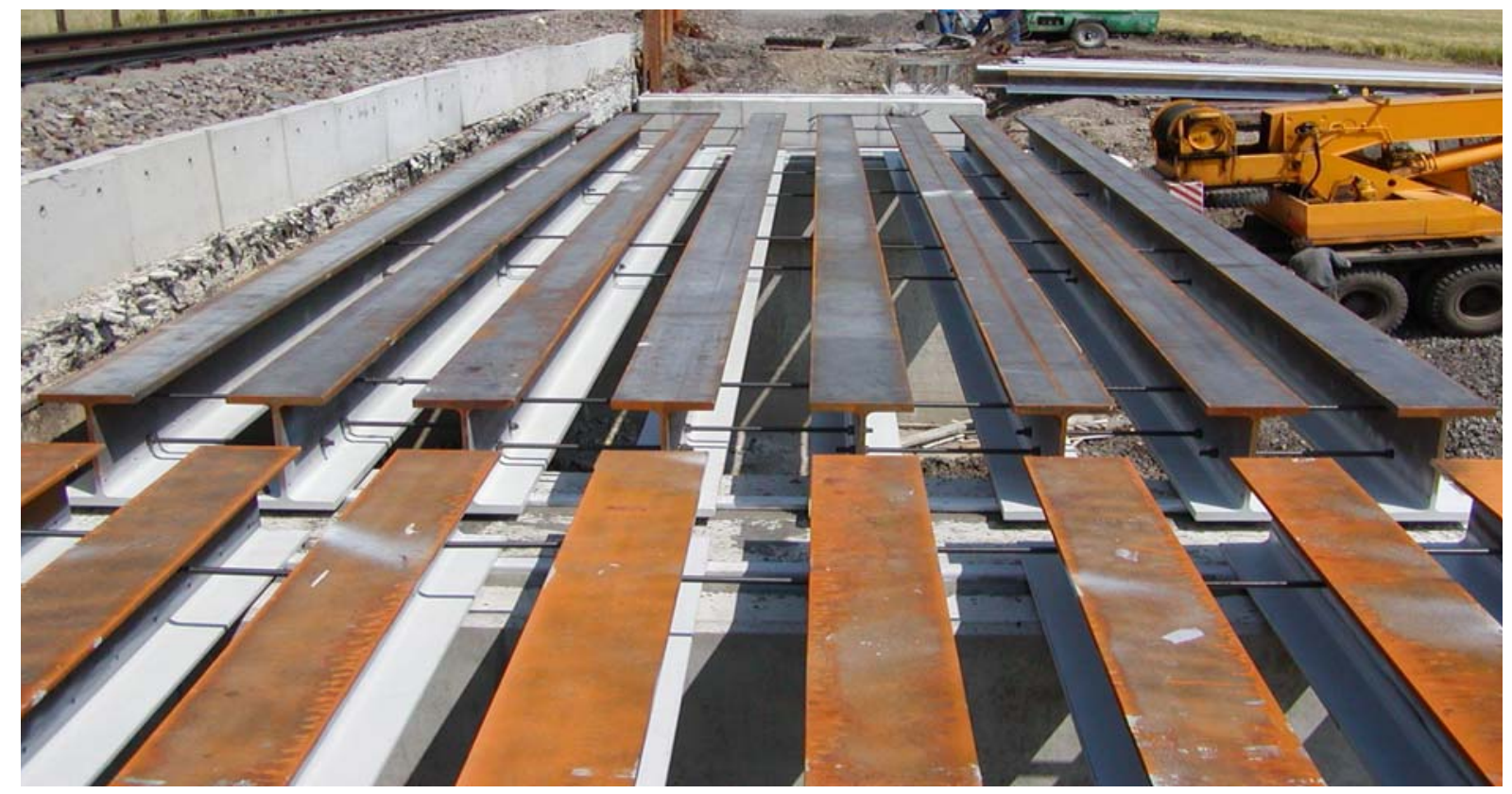

Figure 7: View of the bridge erection 


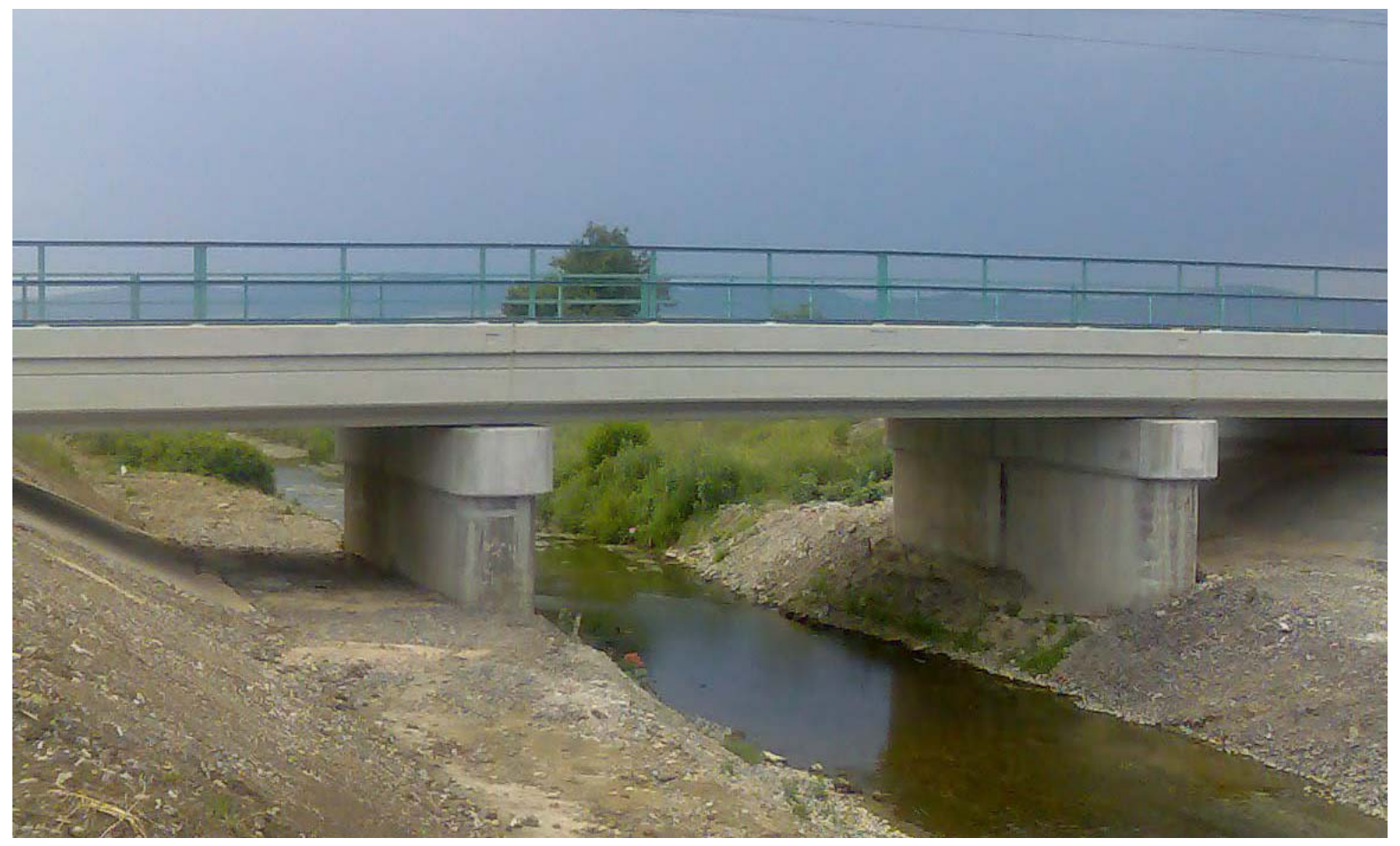

Figure 8: Side view of the restored bridge M1

Of course, also the serviceability limit states have to be verified. Except for deflections, it is necessary to prove the elastic behaviour of structure under the service load. It is up to the designer, whether and to what degree he applies the simplifications relating to the rheology and cracks in concrete, or he determines the stress response of the superstructure to load more accurately.

Considering the plastic bending resistance of the composite cross section, the rheology effects of concrete may be neglected as well as the way of bridge erection. When an elastic bending resistance of the cross section is estimated, the effect of creep and shrinkage of concrete as well as the bridge construction stages (with or without temporary intermediate support) has to be considered.

The bridge construction at the track axis without temporary support is illustrated in Figure 7. The side view of the reconstructed bridge is presented in Figure 8.

\section{Conclusion}

The filler-beam bridges represent an effective and optimal type of bridge structure for bridging short obstacles having length about $6-15 \mathrm{~m}$. This type of bridges joins advantages of application of the continuous ballast bed on the bridge, relatively small construction depth, optimal stiffness for static and dynamic actions and the simple bridge construction as well. In this paper, results of diagnostics and load-carrying capacities determination of three existing filler-beam bridges are presented. It also refers to typical failures and damages of those types 
of bridges and their influence on the bridge deck load-carrying capacity. Concurrently, the paper introduces an example of design of the new filler-beam bridge according to European standards and its specific problems with regard to the cross sectional shape. The paper presents the statement that this type of bridge objects always had, have and obviously will have considerable part in the railway tracks not only in Slovakia. However, it is needed to consider their application in situations when their effectiveness evidently decreases. For example, it relates to the spans $15-20 \mathrm{~m}$, when the weight of filler-beam deck as well as the structural depth significantly increases. The weight of superstructure could be the limiting factor for acceleration of the bridge construction by applying prefabricated filler-beam decks that has direct effect on the length of track possessions and, consequently, on the total cost of reconstruction works.

\section{Acknowledgements}

This paper presents results of works supported by the Slovak Research and Development Agency under the contract No. SUSPP-0005-07 and under the contract No. APVV-0106-11.

\section{References}

[1] UIC, SNF and ARBED. (1997). Design tables for Filler Beam Railway Bridges. Recommendations for design of joist-in-concrete railway bridges. Luxemburg: UIC Code Luxemburg.

[2] Deutsche Bahn. (2000). DS 804. Vorschrift für Eisenbahnbrücken und sonstige Ingenieurbauwerke. Anlage 8 - Eisenbahnbrücken aus Walzträgern in Beton. Regelungen zur Bemessung und baulichen Durchbildung. Deutsche Bahn.

[3] ČD. (2005). MVL 511. Bridge guideline - Superstructures of railway bridges with encased steel beams. Prague: SŽDC Czech Republic.

[4] SUDOP. (1981). Reinforced concrete superstructures of railway bridges. Guideline for design and building. Prague: SUDOP.

[5] CEN 2005. Design of composite steel and concrete structures - Part 2: General rules and rules for bridges. EN 1994-2. Brussels.

[6] SUDOP. (1995). Determination of load-carrying capacity of railway bridges. Operating handbook SR 5. Prague: Czech Railways.

[7] SUTN. (2008). Design of composite steel and concrete structures - Part 2: General rules and rules for bridges. STN EN 1994-2. Bratislava.

[8] SUTN. (1993). Design and evaluation of structures on rebuilding. STN 73 0038. Bratislava.

[9] Vičan, J. et al. (2002). Methodology of calculation of load-carrying capacity of railway bridges. Guideline for Slovak Railways. ŽU Žilina.

[10] Kvočák, V., Kožlejová, V. (2009). Filler beam deck bridges with encased beams of alternative sections. Selected Scientific Papers, Journal of Civil Engineering, Vol. 4, Issue 2, pp 7-15.

[11] Bujňák, J., Odrobiňák, J. (2006). Experimental and theoretical research on real behaviour of composite bridge structures. In Proceedings from International conference on Bridge engineering - Challenges in the 21st century, (pp 450-460). Hong-Kong: Hong-Kong Institution of Engineers. 